\title{
Observation Composed of a Parameter and Chance Error: Determination of the Parameter as Stable Midrange
}

\author{
Dhritikesh Chakrabarty \\ Department of Statistics, Handique Girls' College, Guwahati-781001, Assam, India. \\ e-mail:dhritikesh.c@ rediffmail.com,dhritikeshchakrabarty@gmail.com
}

\begin{abstract}
An analytical method has been developed to determine the true value of the parameter from observations consisting of a common parameter and chance errors since none of the existing statistical methods of estimation can provide the true value of this parameter. The method is based on the stable value of midrange and the symmetry property of normal distribution. This paper describes the development of this method and one numerical application of the method in determining the value of central tendency of each of the annual maximum and the annual minimum of ambient air temperature at Guwahati. Determination of these two values is based on the assumption that the change in each of the annual maximum and the annual minimum of ambient air temperature at Guwahati occurs due to chance cause only but not due to any assignable cause.
\end{abstract}

Key Words: Parameter; Chance Error; Observation; Midrange; Median; Determination Of Parameter.

\section{Introduction}

There are many situations where observations

$$
X_{1}, X_{2}, \ldots \ldots \ldots \ldots \ldots, X_{n}
$$

are composed of some parameter and chance errors i.e.

$$
X_{i}=\mu+\varepsilon_{i}, \quad(i=1,2, \ldots \ldots \ldots, n)
$$

where (i) $\mu$ is the parameter and (ii) $\varepsilon_{i}$ is the chance error associated to $X_{i}$. 
The existing statistical methods of estimation namely least squares method, maximum likelihood method, minimum variance unbiased method, method of moment and method of minimum chi-square provide

$$
\bar{X}=\frac{1}{n}\left(\sum_{i=1}^{n} X_{i}\right)_{i}
$$

as estimator of the parameter $\mu$. This estimator suffers from an error

$$
\overline{\varepsilon_{l}}=\frac{1}{n}\left(\sum_{i=1}^{n} \varepsilon_{i}\right)
$$

which may not be zero [Allan (1962), Barnard (1949), Hald (1999), Ivory (1825), John (2000), Le Cam (1990), Kendall \& Stuart (1977), Lehman \& Casella (1998), Walker \& Lev (1965)]. In other words, none of these methods can provide the true value of the parameter $\mu$. In order to meet up this crisis, an analytical method has already been developed for determining the true value of the parameter $\mu$ in such situation (Chakrabarty, 2014). This method is based on the idea of finding the sufficient shortest interval value for the parameter $\mu$, using order statistics. In this method, it is required to exclude two extreme observations in cumulative manner for computing interval value at every stage in order to obtain the sufficient shortest interval. This method however fails in the situation where insufficient observations are remained after exclusion of the extreme observations at some stage before obtaining the sufficient shortest interval. A method for the same has been developed in order to overcome this inconvenience. This paper is based on the development of another method of the same based on the stable midrange and the symmetry property of normal probability distribution discovered by a German mathematician Carl Friedrich Gauss, the credit for which discovery is also given by some authors to a French mathematician Abraham De Moivre who established that the normal distribution is an approximation to the binomial distribution discovered by James Bernoulli [Bernoulli (1713), Brye (1995), Chakrabarty (2005 , 2008)), De Moivre (1711 , 1718), Hazewinkel (2001), Marsagilla (2004), Stigler (1982), Walker (1985)]. This distribution is described by the probability density function: 


$$
\begin{array}{r}
f(x: \mu, \sigma)=\left\{\sigma(2 \pi)^{1 / 2}\right\}^{-1} \exp \left[-1 / 2\{(x-\mu) / \sigma\}^{2}\right], \\
-\infty<x<\infty,-\infty<\mu<\infty, 0<\sigma<\infty .
\end{array}
$$

Where (i) $X$ is the associated normal variable,

(ii) $\mu$ and $\sigma$ are the two parameters of the distribution and

(iii) Mean of $X=\mu \&$ Standard Deviation of $X=\sigma$.

The distribution is symmetric i.e. its mean, median and mode are equal with each of these three being equal to the stable midrange.

Moreover, the description has been presented on one numerical application of the method in the case of determining the value of central tendency of each of the annual maximum and the annual minimum of ambient air temperature at Guwahati. The determination of these two is based on the assumption that the variation among the observations used in determination occurs due to chance cause only.

\section{Development of the Method}

In the situation under consideration, the observations

$$
X_{1}, X_{2}, \ldots \ldots \ldots, X_{n}
$$

are such that they satisfy

$$
X_{i}=\mu+\varepsilon_{i} \quad, \quad(i=1,2, \ldots \ldots \ldots, n)
$$

Where $\varepsilon_{1}, \varepsilon_{2}, \ldots \ldots \ldots, \varepsilon_{n}$ are values of the chance error variable $\varepsilon$ associated to $X_{1}, X_{2}$ $, \ldots \ldots \ldots \ldots, X_{n}$ respectively.

It is to be noted that

(1) $X_{1}, X_{2}, \ldots \ldots \ldots \ldots, X_{n}$ are known,

(2) $\mu, \varepsilon_{1}, \varepsilon_{2}, \ldots \ldots \ldots \ldots, \varepsilon_{n}$ are unknown

$\&(3)$ the number of linear equations in $(2.1)$ is $n$ with $(n+1)$ unknowns implying that the equations are not solvable mathematically. 
Reasonable facts /Assumptions regarding $\varepsilon_{i}$ :

(1) $\varepsilon_{1}, \varepsilon_{2}, \ldots \ldots \ldots, \varepsilon_{n}$ are unknown values of the variables $\varepsilon$.

(2) The values $\varepsilon_{1}, \varepsilon_{2}, \ldots \ldots \ldots \ldots, \varepsilon_{n}$ are very small relative to the respective values $X_{1}, X_{2}, \ldots \ldots \ldots \ldots, X_{n}$

(3) The variable $\varepsilon$ assumes both positive and negative values.

(4) $P(-a-d a<\varepsilon<-a)=P(a<\varepsilon<a+d a)$ for every real $a$.

(5) $P(a<\varepsilon<a+d a)>P(b<\varepsilon<b+d b)$ $\& P(-a-d a<\varepsilon<-a)<P(-b-d b<\varepsilon<-b)$ for every real positive $a<b$.

(6) The facts (3), (4) \& (5) together imply that $\varepsilon$ obeys the normal probability law.

(7) Sum of all possible values of each $\varepsilon$ is 0 (zero) which together with the fact (6) implies that $E(\varepsilon)=0$.

(8) Standard deviation of $\varepsilon$ is unknown and small, say $\sigma_{\varepsilon}$.

(9) The facts (6), (7) \& (8) together imply that $\varepsilon$ obeys the normal probability law with mean (expectation) 0 \&standard deviation $\sigma_{\varepsilon}$.

$$
\text { Thus, } \varepsilon \sim N\left(0, \sigma_{\varepsilon}\right)
$$

Note (2.1): Since $\varepsilon_{1}, \varepsilon_{2}, \ldots \ldots ., \varepsilon_{n}$ are independently and identically distributed $N\left(0, \sigma_{\varepsilon}\right)$ variates, their mean defined by

$$
\overline{\varepsilon_{l}}=\frac{1}{n}\left(\sum_{i=1}^{n} \varepsilon_{i}\right)
$$

is a $N\left(0, \sigma_{\varepsilon} / \sqrt{ } n\right)$ variate.

\subsection{The Method}

Assumptions (3) \& (4) imply that if the chance error $\varepsilon$ can assume the positive value ' $a$ ' then it can also assume the value ' $-a$ '.

This implies that the midrange of $\varepsilon$ is 0 (zero).

However, the midrange of a few observations on $\varepsilon$ may not be 0 .

But since the distribution of $\varepsilon$ is normal with central tendency 0 , therefore, the distribution of large number (more than 30) of observations on $\varepsilon$ will be approximated by the normal distribution with central tendency 0 and/or the distribution of $n$ observations 
of the chance error $\varepsilon$ will more and more closer to the normal distribution with the same central tendency as $n$ becomes more and more large.

This implies that the midrange of $n$ observations on $\varepsilon$ will be more and more close to 0 as $n$ becomes more and more large. Moreover, if the value of the midrange attains 0 , it will be stable. Thus the stable value of the midrange of the observations on $\varepsilon$ will be the true value of the central tendency of $\varepsilon$. Consequently, the stable value of the midrange of the observations on $X$ will be the true value of the central tendency of $X$.

If the $k$ observations

$$
X_{1}, X_{2}, \ldots \ldots \ldots, X_{k}
$$

are arranged in ascending order of magnitude as

$$
X_{(1)}<X_{(2)}<\ldots \ldots \ldots \ldots<X_{(k)},
$$

then the midrange of the observations is given by

$$
\bar{X}=\frac{1}{2}\left(X_{(1)}+X_{(k)}\right)
$$

\section{Determination of the Central Tendency of the Annual Extremum of the Ambient}

\section{Air Temperature at Guwahati:}

It has been aimed at to search for the true value of central tendency of each of the annual maximum and the annual minimum of ambient air temperature at Guwahati. Here, the term "annual maximum (and/or minimum)" is used to denote the maximum (and/or minimum) occurred during temperature periodic year (i.e. during the period from March of a calendar year to February of the next calendar year). For arriving at the aim, data on these two measures are required. Accordingly, the required data have been collected from the regional meteorological centre, Borjhar, Guwahati. The collected data are the observations on annual maximum and annual minimum of the ambient air temperature at Borjhar (specifically). Data have been found to be available for the period from 1969 to 2013. 
International Journal of Electronics and Applied Research (IJEAR) 2015, vol.2, issue 1

Published Online June 2015 issue (http://eses.co.in/ESES Journal) ISSN NO: 23950064

\subsection{Central Tendency of the Annual Maximum:}

Observed values of the annual maximum of the ambient air Temperature at Guwahati observed during the period from 1969 to 2013 have been collected from the meteorological department of India (Chakrabarty, 2014). These have been presented in Table - I. Computation of the values of the midrange of the cumulative observations has been shown in Table - II.

Table - I

Observed Value on Highest Maximum Temperature (in Degree Celsius) occurred during Temperature Periodic Year

\begin{tabular}{|c|c|c|c|c|c|}
\hline $\begin{array}{l}\text { Year } \\
\text { No }\end{array}$ & $\begin{array}{l}\text { Observed } \\
\text { Value }\end{array}$ & $\begin{array}{c}\text { Calendar Year, Month \& } \\
\text { Date } \\
\text { of occurrence }\end{array}$ & Year No & $\begin{array}{c}\text { Observed } \\
\text { Value }\end{array}$ & $\begin{array}{c}\text { Calendar Year, Month \& } \\
\text { Date } \\
\text { of occurrence }\end{array}$ \\
\hline 1 & 37.1 & 1969, May, 20 & 23 & 37.4 & 1991, July, 20 \\
\hline 2 & 36.6 & 1970, April,01 & 24 & 39.4 & 1992, April, 16 \\
\hline 3 & 36.0 & 1971, March, 27 & 25 & 36.4 & 1993, September, 08 \\
\hline 4 & 35.7 & 1972, July, 14 & 26 & 38.1 & 1994, May, 07 \\
\hline 5 & 39.0 & 1973, April,10 & 27 & 36.3 & 1995, May, 14 \\
\hline 6 & 36.1 & 1974, August, 14 & 28 & 39.9 & 1996, April, 19 \\
\hline 7 & 39.2 & 1975, April, 10 & 29 & 37.4 & 1998, May 21 \\
\hline 8 & 39.0 & 1976, April,17 & 30 & 37.5 & 2000, May, 13 \\
\hline 9 & 35.3 & 1977, August, 14 & 31 & 36.7 & 2001, April,07 \\
\hline 10 & 36.8 & 1978, May, 19 & 32 & 35.5 & 2002, May, 17 \\
\hline 11 & 38.6 & 1979, March, 27 & 33 & 37.4 & 2003, July, 26 \\
\hline 12 & 35.1 & 1980, July, 01 & 34 & 38.0 & 2004, March, 28 \\
\hline 13 & 35.8 & 1981, June, 21 & 35 & 36.6 & 2005, July, 30 \\
\hline 14 & 36.5 & 1982, May, 26 & 36 & 38.0 & 2006, August, 11 \\
\hline 15 & 36.7 & 1983, April, 06 & 37 & 37.3 & 2007, May, 06 \\
\hline 16 & 37.2 & 1984, April, 06 & 38 & 37.3 & 2008, August, 08 \\
\hline 17 & 36.5 & 1985, April,26 & 39 & 38.0 & 2009, May, 23 \\
\hline 18 & 38.4 & 1986, April,03 & 40 & 37.2 & 2010, July, 03 \\
\hline 19 & 37.2 & 1987, May, 19 & 41 & 37.3 & 2011, August, 30 \\
\hline 20 & 36.4 & 1988, August, 03 & 42 & 37.4 & 2012, April,03 \\
\hline 21 & 36.7 & 1989, July, 23 & 43 & 38.8 & 2013, June, 12 \\
\hline 22 & 36.0 & 1990, September, 02 & & & \\
\hline
\end{tabular}


Table - II

Value of Midrange of the Observed Values on Highest Maximum Temperature (in Degree Celsius) occurred during Temperature Periodic Year

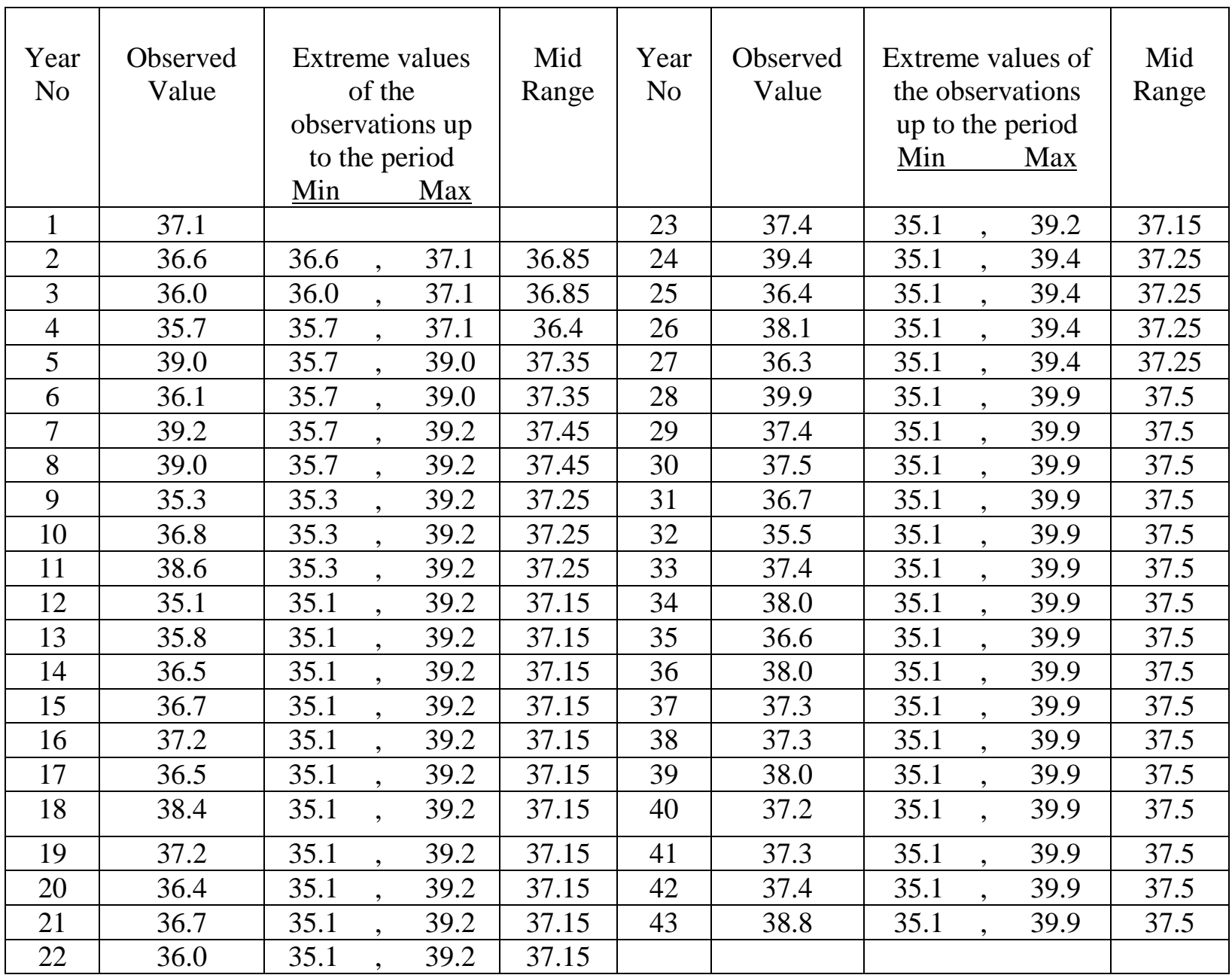

It is observed in Table -II that from the temperature periodic year number 30 onwards the value of the midrange has become stable with the stabilized value 37.5. One can observe that 29 observations lie below 37.5 and 12 observations lie above 37.5. Thus, 37.5 cannot be the median. Therefore, by the symmetric property of normal distribution, 
International Journal of Electronics and Applied Research (IJEAR) 2015, vol.2, issue 1

Published Online June 2015 issue (http://eses.co.in/ESES Journal) ISSN NO: 23950064

the central tendency of the annual maximum of the ambient air temperature at Guwahati cannot be 37.5 degree Celsius.

However, if the most extreme (highest) observation " 39.9 " is excluded then the values of the midrange obtained have been shown in Table -III. In Table-III, it is found that 20 observations lie below 37.2 and 20 observations above the observation " 37.2 " and also, the observation "37.2" has appeared thrice. Thus " 37.2 " is the median of the observations. Moreover, in this case, the stable value of the midrange from the periodic year number 30 onwards is 37.25 .

Table - III

Value of Midrange of the Observed Values on Highest Maximum Temperature (in

Degree Celsius) occurred during Temperature Periodic Year

\begin{tabular}{|c|c|c|c|c|c|c|c|c|c|}
\hline $\begin{array}{l}\text { Year } \\
\text { No }\end{array}$ & $\begin{array}{l}\text { Observed } \\
\text { Value }\end{array}$ & $\begin{array}{l}\text { Extrem } \\
\text { the obs } \\
\text { up to } t \\
\text { Min } \\
\end{array}$ & $\begin{array}{l}\text { lues of } \\
\text { ations } \\
\text { period } \\
\text { Max }\end{array}$ & $\begin{array}{l}\text { Mid } \\
\text { Range }\end{array}$ & $\begin{array}{l}\text { Year } \\
\text { No }\end{array}$ & $\begin{array}{l}\text { Observed } \\
\text { Value }\end{array}$ & \multicolumn{2}{|c|}{$\begin{array}{l}\text { Extreme values of } \\
\text { the observations } \\
\text { up to the period } \\
\text { Min Max }\end{array}$} & $\begin{array}{l}\text { Mid } \\
\text { Range }\end{array}$ \\
\hline 1 & 37.1 & & & & 23 & 37.4 & 35.1 & 39.2 & 37.15 \\
\hline 2 & 36.6 & 36.6 & 37.1 & 36.85 & 24 & 39.4 & 35.1 & 39.4 & 37.25 \\
\hline 3 & 36.0 & 36.0 & 37.1 & 36.85 & 25 & 36.4 & 35.1 & 39.4 & 37.25 \\
\hline 4 & 35.7 & 35.7 & 37.1 & 36.4 & 26 & 38.1 & 35.1 & 39.4 & 37.25 \\
\hline 5 & 39.0 & 35.7 & 39.0 & 37.35 & 27 & 36.3 & 35.1 & 39.4 & 37.25 \\
\hline 6 & 36.1 & 35.7 & 39.0 & 37.35 & 28 & - & & & - \\
\hline 7 & 39.2 & 35.7 & 39.2 & 37.45 & 29 & 37.4 & 35.1 & 39.4 & 37.25 \\
\hline 8 & 39.0 & 35.7 & 39.2 & 37.45 & 30 & 37.5 & 35.1 & 39.4 & 37.25 \\
\hline 9 & 35.3 & 35.3 & 39.2 & 37.25 & 31 & 36.7 & 35.1 & 39.4 & 37.25 \\
\hline 10 & 36.8 & 35.3 & 39.2 & 37.25 & 32 & 35.5 & 35.1 & 39.4 & 37.25 \\
\hline 11 & 38.6 & 35.3 & 39.2 & 37.25 & 33 & 37.4 & 35.1 & 39.4 & 37.25 \\
\hline 12 & 35.1 & 35.1 & 39.2 & 37.15 & 34 & 38.0 & 35.1 & 39.4 & 37.25 \\
\hline 13 & 35.8 & 35.1 & 39.2 & 37.15 & 35 & 36.6 & 35.1 & 39.4 & 37.25 \\
\hline 14 & 36.5 & 35.1 & 39.2 & 37.15 & 36 & 38.0 & 35.1 & 39.4 & 37.25 \\
\hline 15 & 36.7 & 35.1 & 39.2 & 37.15 & 37 & 37.3 & 35.1 & 39.4 & 37.25 \\
\hline 16 & 37.2 & 35.1 & 39.2 & 37.15 & 38 & 37.3 & 35.1 & 39.4 & 37.25 \\
\hline 17 & 36.5 & 35.1 & 39.2 & 37.15 & 39 & 38.0 & 35.1 & 39.4 & 37.25 \\
\hline 18 & 38.4 & 35.1 & 39.2 & 37.15 & 40 & 37.2 & 35.1 & 39.4 & 37.25 \\
\hline 19 & 37.2 & 35.1 & 39.2 & 37.15 & 41 & 37.3 & 35.1 & 39.4 & 37.25 \\
\hline 20 & 36.4 & 35.1 & 39.2 & 37.15 & 42 & 37.4 & 35.1 & 39.4 & 37.25 \\
\hline 21 & 36.7 & 35.1 & 39.2 & 37.15 & 43 & 38.8 & 35.1 & 39.4 & 37.25 \\
\hline 22 & 36.0 & 35.1 & 39.2 & 37.15 & & & & & \\
\hline
\end{tabular}


Therefore, by the symmetric property of normal distribution, the central tendency of the annual maximum of the ambient air temperature at Guwahati can be regarded as 37.2 degree Celsius.

\subsection{Central Tendency of the Annual Minimum:}

Observed values of the annual minimum of the ambient air Temperature at Guwahati observed during the period from 1969 to 2013 have been collected from the meteorological department of India (Chakrabarty, 2014). These have been presented in Table - IV. Computation of the values of the midrange of the cumulative observations has been shown in Table $-\mathrm{V}$.

Table - IV

Observed Value on Lowest Minimum Temperature (in Degree Celsius) occurred during Temperature Periodic Year

\begin{tabular}{|c|c|c|c|c|c|}
\hline $\begin{array}{l}\text { Year } \\
\text { No }\end{array}$ & $\begin{array}{l}\text { Observed } \\
\text { Value }\end{array}$ & $\begin{array}{c}\text { Calendar Year, Month \& } \\
\text { Date of occurrence }\end{array}$ & $\begin{array}{l}\text { Year } \\
\text { No }\end{array}$ & $\begin{array}{l}\text { Observed } \\
\text { Value }\end{array}$ & $\begin{array}{c}\text { Calendar Year, Month \& } \\
\text { Date of occurrence }\end{array}$ \\
\hline 1 & 6.6 & 1969, January,16 & 23 & 7.4 & 1991, January, 20 \\
\hline 2 & 6.6 & 1969, December, 27 & 24 & 5.9 & 1992, January, 05 \\
\hline 3 & 5.9 & $\begin{array}{c}\text { 1971, January, } 31 \\
\text { \& February, } 01\end{array}$ & 25 & 8.4 & 1993, February, 23 \\
\hline 4 & 8.2 & 1972, January, 21 & 26 & 7.8 & 1993, December, 27 \\
\hline 5 & 5.0 & 1973, February, 03 & 27 & 7.5 & 1995, January, 22 \\
\hline 6 & 6.3 & 1974, February, 07 & 28 & 9.4 & 1996, January,19 \\
\hline 7 & 7.4 & 1975, January, 19 & 29 & NA & NA \\
\hline 8 & 6.6 & 1976, January, 22 & 30 & NA & NA \\
\hline 9 & 6.2 & 1977, January, 30 & 31 & NA & NA \\
\hline 10 & 7.3 & 1978, January, 12 & 32 & 8.9 & 2001, January, 08 \\
\hline 11 & 6.2 & 1979, January,09 & 33 & 8.6 & 2002, January, 26 \\
\hline 12 & 6.4 & 1980, February, 08 & 34 & 8.0 & 2003, January, 16 \\
\hline 13 & 7.5 & 1981, January,10 & 35 & 7.9 & 2004, February, 04 \\
\hline 14 & 8.3 & 1982, February, 07 & 36 & 6.7 & 2004, December, 27 \\
\hline 15 & 4.9 & 1983, January, 06 & 37 & 9.6 & 2006, January, 12 \\
\hline 16 & 6.1 & 1984, January, 30 & 38 & 6.4 & 2007, January, 18 \\
\hline 17 & 7.8 & 1985, January, 19 & 39 & 7.8 & 2008, February, 03 \\
\hline 18 & 8.6 & 1986, January, 20 & 40 & 9.9 & 2009, January, 07 \\
\hline 19 & 7.7 & 1987, January, 05 & 41 & 8.6 & 2010, January, 03 \\
\hline 20 & 9.2 & 1988, January, 01 & 42 & 7.0 & 2011, January, 21 \\
\hline 21 & 6.7 & 1989, January, 14 & 43 & 6.4 & 2012, January, 15 \\
\hline 22 & 8.6 & 1989, December, 31 & 44 & 5.6 & 2013, January, 11 \\
\hline
\end{tabular}


International Journal of Electronics and Applied Research (IJEAR) 2015, vol.2, issue 1

Published Online June 2015 issue (http://eses.co.in/ESES Journal) ISSN NO: 23950064

Table $-\mathrm{V}$

Value of Midrange of the Observed Values on Lowest Minimum Temperature (in Degree

Celsius) occurred during Temperature Periodic Year

\begin{tabular}{|c|c|c|c|c|c|c|c|c|c|}
\hline \multirow{2}{*}{$\begin{array}{c}\text { Year } \\
\text { No } \\
\\
1 \\
\end{array}$} & \multirow{2}{*}{$\begin{array}{c}\text { Observed } \\
\text { Value } \\
\\
6.6\end{array}$} & \multicolumn{2}{|c|}{$\begin{array}{l}\text { Extreme values of } \\
\text { the observations } \\
\text { up to the period } \\
\text { Min Max }\end{array}$} & \multirow[t]{2}{*}{$\begin{array}{c}\text { Mid } \\
\text { Range }\end{array}$} & $\begin{array}{c}\text { Year } \\
\text { No }\end{array}$ & $\begin{array}{c}\text { Observed } \\
\text { Value }\end{array}$ & \multicolumn{2}{|c|}{$\begin{array}{l}\text { Extreme values of } \\
\text { the observations } \\
\text { up to the period } \\
\text { Min Max }\end{array}$} & $\begin{array}{c}\text { Mid } \\
\text { Range }\end{array}$ \\
\hline & & & & & 23 & 7.4 & 4.9 & 9.2 & 7.05 \\
\hline 2 & 6.6 & & & & 24 & 5.9 & 4.9 & 9.2 & 7.05 \\
\hline 3 & 5.9 & 5.9 & 6.6 & 6.25 & 25 & 8.4 & 4.9 & 9.2 & 7.05 \\
\hline 4 & 8.2 & 5.9 & 6.6 & 6.25 & 26 & 7.8 & 4.9 & 9.2 & 7.05 \\
\hline 5 & 5.0 & 5.0 & 6.6 & 5.8 & 27 & 7.5 & 4.9 & 9.2 & 7.05 \\
\hline 6 & 6.3 & 5.0 & 6.6 & 5.8 & 28 & 9.4 & 4.9 & 9.4 & 7.15 \\
\hline 7 & 7.4 & 5.0 & 7.4 & 6.2 & 29 & 8.3 & 4.9 & 9.4 & 7.15 \\
\hline 8 & 6.6 & 5.0 & 7.4 & 6.2 & 30 & 8.9 & 4.9 & 9.4 & 7.15 \\
\hline 9 & 6.2 & 5.0 & 7.4 & 6.2 & 31 & 8.6 & 4.9 & 9.4 & 7.15 \\
\hline 10 & 7.3 & 5.0 & 7.4 & 6.2 & 32 & 8.0 & 4.9 & 9.4 & 7.15 \\
\hline 11 & 6.2 & 5.0 & 7.4 & 6.2 & 33 & 7.9 & 4.9 & 9.4 & 7.15 \\
\hline 12 & 6.4 & 5.0 & 7.4 & 6.2 & 34 & 6.7 & 4.9 & 9.4 & 7.15 \\
\hline 13 & 7.5 & 5.0 & 7.5 & 6.25 & 35 & 9.6 & 4.9 & 9.6 & 7.25 \\
\hline 14 & 8.3 & 5.0 & 8.3 & 6.65 & 36 & 6.4 & 4.9 & 9.6 & 7.25 \\
\hline 15 & 4.9 & 4.9 & 8.3 & 6.6 & 37 & 7.8 & 4.9 & 9.6 & 7.25 \\
\hline 16 & 6.1 & 4.9 & 8.3 & 6.6 & 38 & 9.9 & 4.9 & 9.9 & 7.4 \\
\hline 17 & 7.8 & 4.9 & 8.3 & 6.6 & 39 & 8.6 & 4.9 & 9.9 & 7.4 \\
\hline 18 & 8.6 & 4.9 & 8.6 & 6,75 & 40 & 7.0 & 4.9 & 9.9 & 7.4 \\
\hline 19 & 7.7 & 4.9 & 8.6 & 6,75 & 41 & 6.4 & 4.9 & 9.9 & 7.4 \\
\hline 20 & 9.2 & 4.9 & 9.2 & 7.05 & 42 & 5.6 & 4.9 & 9.9 & 7.4 \\
\hline 21 & 6.7 & 4.9 & 9.2 & 7.05 & 43 & & & & \\
\hline 22 & 8.6 & 4.9 & 9.2 & 7.05 & 44 & & & & \\
\hline
\end{tabular}

It is observed in Table $-\mathrm{V}$, that from the temperature periodic year number 31 , the value of the midrange has become stable with the stabilized value 7.15 up to the period number 39 and then again from the year number 40 onwards the value of the midrange has become stable with the stabilized value 7.4. One can observe that 19 observations lie below 7.4 and 19 observations lie above 7.5 whereas each of " 7.4 " and " 75 " occurs 2 times. Thus, median of the observations lies between 7.4 and 75

i.e. $7.4<$ Median $<7.5$ 
Now, since the value of the midrange for large number $(\geq 38)$ of observations has been found as 7.4 and the median of them as just greater than 7.4 but less than 7.5 the value of the central tendency of the observations by the symmetric property of normal distribution, will be 7.4 .

Again, if the observations are arranged in order, the observation ' 7.4 ' lies at the middle position. This also means, 7.4 is the median of the observations. Therefore, by the symmetric property of normal distribution, the central tendency of the annual maximum of the ambient air temperature at Guwahati can be regarded as 7.4 degree Celsius.

\section{Conclusion}

The method can yield the true value of the central tendency in the situation where variation among the observations on the associated variable occurs due to chance cause only. Each of the existing statistical methods of estimation provides an estimate of the central tendency in such situation which suffers from an error though may be small. Moreover, the amount of error involved in this estimate is unknown. The method developed here provides an estimate which is free from error.

For a normal distribution mean, median and median are equal. Each of them is a measure of central tendency. It seems that there exists some method of determination of central tendency in the same situation. Thus, it is a problem for the researchers at this stage to search for whether there exists method for the same based on mean, median and mode as well as to discover the hidden method if exists.

The estimation of central tendency of the extremum of ambient air temperature at Guwahati is based on the assumption that change in temperature at this location over years during the period for which data are available occurs due to chance cause only but not due to any assignable cause. Thus if the assumption is true, the values of the central tendency of annual maximum and annual minimum of the ambient air temperature at Guwahati namely 37.2 Degree Celsius and 7.4 Degree Celsius respectively, as obtained in this study, are acceptable. However, it is yet to examine whether the assumption upon which the current study is based is true. 


\section{References}

Allan B., On the Foundations of Statistical Inference" Journal of the American Statistical Association, vol. 57, pp. 269 - 306, 1962.

Barnard G. A., Statistical Inference, Journal of the Royal Statistical Society, Series B, vol. 11, pp. $115-149,1949$.

Brye W., The Normal Distribution: Characterizations with Applications, published by Springer Verlag, ISBN 0 - 387 - 97990 - 5. 1995.

Bernoulli J., Arts Conjectandi, published by Impensis Thurmisiorum Fratrum Basileae. 1713.

Chakrabarty D., Probability: Link between the Classical Definition and the Empirical Definition, J. Ass. Sc. Soc., 45, 13-18, June 2005.

Chakrabarty D., Bernoulli's Definition of Probability: Special Case of Its Chakrabarty's Definition, Int. J. Agricult. Stat. Sci., 4(1), 23 - 27, 2008.

Chakrabarty D., "Temperature in Assam: Natural Extreme Value”, J. Chem. Bio. Phy. Sci. Sec. C, 2014, 4(2), $14797-488$.

Chakrabarty D., "Natural Interval of Monthly Extreme Temperature in the Context of Assam", J. Chem. Bio. Phy. Sci. Sec. C, 2014, 4(3), 2424 - 2433.

Chakrabarty D., "Analysis of Errors ssociated to Observations of Measurement Type", International Journal of Electronics and Applied Research, vol. 1. no. 1, pp. 15 - 28, 2014.

Chakrabarty D., "Determination of Parameter from Observations Composed of Itself and Errors ", International Journal of Engineering Science and Innovative Technology, vol. 3, no. 2, pp. $304-311,2014$.

De Moivre A., De Mensura Sortis, published by Philosophical Transaction of the Royal Society, 1711.

De Moivre A., The Doctrine of Chances, 1st Edition (2nd Edition in 1738 \& 3rd Edition in 1756), ISBN $0-8218-2103-2.1718$.

Hald A., On the History of Maximum Likelihood in Relation to Inverse Probability and Least Squares, Statistical Science, vol. 14, pp. 214 - 222, 1999. 
Hazewinkel M., Normal Distribution, Encyclopedia of Mathematics, Springer, ISBN 978 $-1-55608-010-4,2001$.

Ivory, On the Method of Least Squares, Phil. Mag., vol. LXV, pp. 3 - 10, 1825.

John A., Fisher's Inverse Probability of 1930, International Statistical Review, vol. 68, pp. $155-172,2000$.

Kendall M. G. and Stuart A., Advanced Theory of Statistics, Vol. 1 \& 2, $4^{\text {th }}$ Edition, New York, Hafner Press, 1977.

Le Cam L., Maximum likelihood — an introduction, ISI Review, vol. 58, no. 2, pp. 153 $171,1990$.

Lehmann E. L. \& Casella G, “ Theory of Point Estimation”, 2nd ed. Springer. ISBN 0 $387-98502-6,1998$.

Marsagilia G., Evaluating the Normal Distribution, Journal of Statistical Software, 11 (4), 2004.

Stigler S. M., A Modest Proposal : A New Standard for the Normal, The American Statistician, 36 (2), 137 - 138, 1982.

Walker H. M., De Moivre on the Law of Normal Probability, In Smith, David Eugene. A Source Book in Mathematics, Dover, ISBN 0 - 486 - 64690 - 4, 1985.

Walker H. M. \& Lev J., Statistical Inference, Oxford \& IBH Publishing Company. 1965. 